\title{
Executive functions in the young elderly and oldest old: a preliminary comparison emphasizing decision making
}

\author{
Daniela Schneider Bakos, Maria Clara Pinheiro de Paula Couto, Wilson Vieira Melo, Maria \\ Alice de M. P. Parente, Silvia H. Koller and Lisiane Bizarro \\ Universidade Federal do Rio Grande do Sul, Brasil
}

\begin{abstract}
This study aimed at investigating differences in the performance of the young elderly and oldest old in tasks evaluating cognitive flexibility/inhibition (Stroop test), selective attention/working memory (Digit Span Subtest), premorbid intelligence/semantic knowledge (Vocabulary Subtest), and decision making (Iowa Gambling Task - IGT). Twenty healthy individuals were divided into two groups: 10 young elderly $(M=62$ years, $S D=2.1)$ and 10 oldest old $(M=80$ years, $S D=3.3)$, both with high educational level $(M=14$ years of study, $S D=2.5)$. Results showed that the groups were only different in terms of decision making. There was also a difference in the learning process of each group; the young elderly reached more favorable scores in the IGT. Keywords: executive functions, oldest old, decision making, IGT.
\end{abstract}

Received 24 September 2008; received in revised form 9 December 2008 ; accepted 9 December 2008. Available online 29 December 2008.

\section{Introduction}

Increase in longevity demands studies aiming at a wider and well-founded understanding of the various factors that accompany the aging process (Baldelli, Salvioli, Neri, \& Pradelli, 1996). The proportion of elderly in the population was $10.5 \%$ in developed countries until 1975 , and about $3.8 \%$ in developing countries. It is estimated that by 2025 these rates will reach $16.5 \%$ and $7.5 \%$ in developed and developing countries, respectively (Xavier, Ferraz, Bisol, Fernandes, Schwanke, \& Moriguchi, 2000). This means that an increase of around $60 \%$ may be seen in the elderly population in developed countries, and even higher rates - about $97.4 \%$ - in the same age group in developing countries. Therefore, it is important to have a better understanding of third age features since, in other words, this means improving the quality of life of the aging population.

It is known that the aging process is characterized by several psychological and biological changes, among which are changes in cognitive functioning (Baldelli

Daniela Schneider Bakos, Maria Clara Pinheiro de Paula Couto, Wilson Vieira Melo, Maria Alice de M. P. Parente, Silvia H. Koller and Lisiane Bizarro, Graduate Program in Psychology, Institute of Psychology, Universidade Federal do Rio Grande do Sul. Correspondence regarding this article should be directed to Maria Clara Pinheiro de Paula Couto Rua Ramiro Barcelos 2600 sala 104, Rio Branco, CEP: 90035-003 - Porto Alegre, RS - Brazil CEP 90040-341. E-mail: mariaclara.ppc@gmail.com et al., 1996; Lindenberger \& Baltes, 1997; Mungas, Reed, \& Kramer, 2003). Based on the agreement found in a number of studies, it is possible to state that a certain cognitive impairment seems to be a universal phenomenon in the elderly. Currently it is quite clear that this decline is related to neuroanatomical, biochemical and electrophysiological changes, more specifically in the frontal lobe, and particularly in its most anterior portion, the prefrontal cortex. Cognitive skills, called executive functions, depend on the integrity of this region (Cowell et al., 1994; Haug \& Eggers, 1991; Parkin, 1993; Raz et al., 1997, 2005; West, 1996, 2000).

Executive functions are understood as a set of processes involved in the control and regulation of simple cognitive actions, as well as goal-directed and futureoriented behaviors. It is a multidimensional construct, and can be understood as having four components, namely, volition, planning, purposive action and effective performance (Lezak, 1995; Spreen \& Strauss, 1998). These components often involve attention and working memory, cognitive flexibility, decision making, judgment, and behavioral regulation. Many studies have shown a major impairment in these cognitive functions commonly found in the elderly (Carey et. al, 2008; Lindenberger \& Baltes, 1997; Mungas et al., 2003; Smith \& Baltes, 1997).

Several research studies have investigated the components of these executive processes in the elderly and have found major impairments regarding memory (Spencer \& Raz, 1994), learning ability, and cognitive 
flexibility (Finuncane et al., 2002; Wecker, Kramer, Hallam, \& Delis, 2005; Yang, Krampe, \& Baltes, 2006). In addition, deficits in judgment ability and decision making have been equally found in this population, showing more disadvantageous choices in the elderly when compared with young individuals (Deakin, Aitken, Robbins, \& Sahakian, 2004; Fein, McGillivray, \& Finn, 2007; Denburg, Tranel, \& Bechara, 2005).

In regards to attention, measured by the Stroop test (Stroop, 1935), results form a contradictory scenario. Impairment in this cognitive process is found through investigations comparing young and elderly individuals as to their performance in the test (Verhaeghen \& De Meersman, 1998). However, there are no discrepancies when these comparisons are restricted to elderly populations, such as young elderly and the oldest old (Lin, Chan, Zheng, Yang, \& Wang, 2007; Shilling, Chetwynd, \& Rabbitt, 2002).

Given this clear cognitive decline related to aging processes, current studies on aging have shown a growing interest in a segment of the population identified as the "fourth age," or also the oldest old (Baltes, 1998). Population estimates point out to the growth of this subgroup, suggesting its increasing representativeness among individuals. Furthermore, it has been suggested that this group has important differences compared with younger elderly individuals, but the incipience of such investigations does not allow for interrater agreement (Baltes \& Smith, 1997). Although there is no consensus as to the specific age individuals start being considered as the oldest old, conception is that this classification is marked by the 75 years of age (Baltes, 1998; Singer, Lindberger, \& Baltes, 2003).

Despite a series of studies investigating executive functioning throughout development, few have dealt with executive functions in the subgroup of the oldest old (Glisky \& Kong, 2008; Hoshide et. al, 2008). In general, there is a lack of studies comparing the young elderly and the oldest old, which prevents obtaining empirically validated data on the difference between these groups. A study conducted by Yang, Krampe and Baltes (2006) compared the young elderly and the oldest old as to their learning ability and cognitive plasticity. The results showed evidence of a continued plasticity in the elderly group, which was extended to the subgroup of the oldest old. In accordance, Singer, Lindenberger and Baltes (2003) observed a preserved cognitive plasticity in the oldest old. However, the authors also found that this preservation occurs at a much lower degree in this subgroup when it was compared with the subgroup of young elderly.

A Brazilian study evaluated memory, attention and verbal fluency (Argimon \& Stein, 2005) in healthy elderly individuals aged 80 years and older (mean schooling of 2.5 years) at two distinct times with a 3-year interval. The sample performance in these tests was discussed, considering the participants' educational level. There was higher preservation of cognitive functions in the elderly who had higher educational level. A similar investigation evaluated individuals older than 80 years with low educational level from different Brazilian regions as to their verbal memory (immediate and late recall), working memory, attention and verbal fluency skills (Xavier et al., 2006). The findings showed worse performance in working memory, attention and verbal fluency when compared with more educated populations. The results mentioned above corroborate previous studies showing a protective factor of schooling throughout time in certain cognitive functions. Thus, in addition to the age factor, which has been properly documented in the literature as associated with changes in cognitive performance, there is evidence that more years of study are associated with slower cognitive decline (Ardila et al., 2000, Lin et al., 2007; Moering, Schinka, Mortimer, \& Graves, 2004; Van der Elst, Van Boxtel, Van Breukelen, \& Jolles, 2006). Although the influence of education on cognitive performance has been reported in several studies, significant misunderstanding exists with regard to this relation (for a review, see Ardila et al., 2000).

Due to the demand for further studies on the oldest old, especially on those who have a high educational level, the present study aimed at investigating the executive functioning of these individuals in an educated sample. It also approached the presence of differences in the performance of the young elderly and oldest old in tasks evaluating cognitive flexibility/inhibition (Stroop test), selective attention/working memory (Digit Span Subtest), premorbid intelligence/semantic knowledge (Vocabulary Subtest), and decision making (Iowa Gambling Task - IGT). Since the group of the oldest old is representative of a higher population increase among elderly individuals, it is necessary to have a better understanding of the influence of aging on their cognitive functioning, aiming at improving intervention resources towards a better quality of life in this population.

\section{Method}

\section{Study design}

This study used a quasi-experimental control design with posttest only. Participants were selected through the non-randomized convenience sampling technique.

\section{Participants}

Twenty healthy individuals, mostly female (90\%), aged 60-84 years, were recruited for the study. The sample was divided into two groups according to age: Group $1-10$ young elderly, aged 60-67 years $(M=62$, $S D=2.1$ ) and Group 2 -10 oldest old, aged 75-84 years $(M=79.6, S D=3.3)$. The participants belonged mainly to socioeconomic classes A (70\%) and B (25\%). Both groups were not different as to the variables gender and educational level. There were nine women and one 
man in each group. Educational level was not different between both groups $(t(18)=1.94, p<.07)$.

Inclusion criteria were a 24 cut-off point in the MiniMental State Examination (MMSE) and educational level higher than 9 years. No participants scored less than the cut-off point in the MMSE. Mean sample score was 28.5 $(S D=1.6)$. Mean schooling years for the sample was high $(M=14.05, S D=2.5)$ when compared with the educational level of elderly Brazilians in general (according to data from the IBGE, PNAD, 2002-2003, mean number of schooling years in people aged 60 years or more in Brazil is 3.4). Exclusion criteria were individuals with any Axis I psychiatric diagnosis according to the DSM-IV-TR (APA, 2002), presence of dementia, and severe untreated sight and hearing disorders. Regarding to medication use, participants taking other than blood pressure medication didn't take part in the study. In addition, familiarity with the tests used, as obtained by the sociocultural questionnaire, was also considered as an exclusion criterion.

\section{Instruments}

\section{Sociocultural Questionnaire}

This aimed at providing a socioeconomic characterization of the sample. This questionnaire was developed as an adaptation of the questionnaire used by the Neuropsycholinguistics Laboratory of the UFRGS, and was divided into two parts. Part "A", which was used in the present study, collects identification data from the participants, including information regarding age, educational level, work activity, health, socioeconomic level, and familiarity with investment activities and gambling practice. It is a structured interview composed by clear and brief questions whose application had an approximate duration of 10 minutes.

\section{Modified Mini International Neuropsychiatry Interview (MINI)}

The MINI was used to investigate the main Axis I psychiatric disorders. It consists of a brief structured interview, following diagnostic criteria similar to those found in the DSM-IV-TR (Diagnostic and Statistical Manual of Mental Disorders) and in the ICD-10 (International Classification of Diseases, $10^{\text {th }}$ revision). The MINI was developed by Sheehan, et al. (1998) and the current version was validated with samples from different countries. In Brazil, it was validated by Amorim (2000). This study used all the scales. The application was conducted by the rater and lasted 15 minutes on average.

\section{Mini-Mental State Examination (MMSE)}

This instrument, universally used to screen dementia processes, was applied to the group of elderly individuals in order to exclude those who had positive criteria for dementia. The MMSE is a brief mental health examination, adapted to Portuguese and for the population of Porto Alegre by Chaves and Izquierdo (1992). It assesses five cognitive areas: orientation, registration, attention and calculation, recall, and language. The time to complete the instrument was approximately 10 minutes in both groups of elderly individuals. The cut-off point set for this sample was $>24$ points, according to the study by Chaves and Izquierdo (1992) in the population of Porto Alegre.

\section{Digit Span Subtest}

The Digit Span Subtest is one of the tests of the Wechsler Adult Intelligence Scale (WAIS-III) (Wechsler, 1997), adapted for the Brazilian population by Nascimento (2000). This research used the Digit Span Subtest as a measurement of attention and working memory (Cunha, 2000; Wechsler, 1997). This subtest comprehends two different tests: Direct Digit Span and Reverse Digit Span, each comprising distinct cognitive processes. Both consist of evoking sequences of numbers and demand attention span, besides depending on an ability of retaining immediate memory. However, the Direct Digit Span is more directly related to attention aspects, while the Reverse Digit Span involves reversibility and working memory skills. Test application lasted 5 minutes on average, and had a final score obtained from the Direct and Reverse Digit Spans. This final score is obtained through the sum of correct answers on both the direct and indirect span.

\section{Vocabulary Subtest}

The Vocabulary Subtest is one of the tests included in the Wechsler Adult Intelligence Scale (WAISIII) (Wechsler, 1997), used in this study to measure semantic knowledge and understanding (Cunha, 2000; Wechsler, 1997). It consists of a list of words for which the participant should present a concept, such as "What does cent mean?". The concepts are analyzed according to definitions in Portuguese dictionaries and can be scored as 0,1 and 2 . The test was performed by the researcher and lasted approximately 15 minutes.

\section{Stroop Test}

The Stroop test was developed by Stroop (1935) and later modified by Golden (1978). This task aims at evaluating cognitive flexibility (cognitive control in inhibition of usual response) and selective attention. The test is divided into three parts: (1) in the first part, the participant should read aloud the words "red," "green," and "blue" printed in black on a white background; (2) in the second part, the participant is requested to name the colors of sequences of 100 "Xs" printed in red, green and blue; and (3) in the third and last part, the participant is confronted with names of colors (red, green and blue) printed in colors that do not match the word, in which the color of the printed word should be named, instead of reading the word itself. The test lasted approximately 5 minutes. The performance was analyzed according to the sum of correct answers on each part of the test. 


\section{Iowa Gambling Task (IGT)}

The IGT was originally developed by Bechara, Damasio, Damasio and Anderson (1994) and adapted by Schneider and Parente (2006). It consists of a computerized version of the original task, used to evaluate the individual's ability to choose between immediate rewards and negative long-term consequences, in the presence of a complex context of varied reward and punishment contingencies. It is known to involve two different aspects of executive function: the intuitive system and the reasoning system (Kahneman, 2003). The intuitive system functions more automatically and laden with emotional valence, whereas the reasoning system is based on more deliberate processes associated with reasoning operations. It was used in the present study to measure the participants' executive functions, based on their decision-making capacity.

The participants should choose between four decks of cards (A, B, C, D), two of which led to high immediate gains, but large losses, and two other decks with low immediate gains, but lower future losses. Such reward and punishment mechanism, which is preprogrammed and unknown by the participant, is organized so that decks " $\mathrm{A}$ " and " $\mathrm{B}$ " generate long-term losses and are, therefore, considered disadvantageous, whereas decks " $\mathrm{C}$ " and " $\mathrm{D}$ " include longterm gains, which characterize them as advantageous.

The participants were requested to perform a series of 100 card choices. However, they were not aware of how many selections they had to make. They were told that the objective of the game was to maximize gains, gathering as much "money" as possible. The desired card could be selected at any time, freely changing the choice throughout the task. The task lasted about 20 minutes and was conducted by the researcher. In terms of results, some scores are indirect, based on the number of cards the participant took from each deck.

\section{Procedures}

Participation in this study was voluntary, and all participants signed a consent form. This document aims at informing the participants about the objectives, justifications, and procedures of this investigation. It ensures data confidentiality and the individual's guarantee of receiving a feedback of their performance. The participants were aware of their right to quit the research at any time. The project was approved by the Research Ethics Committee of the Institute of Psychology, UFRGS, under registration number 2006/005.

The participants were contacted in elderly socialization centers from the population of Porto Alegre. The objectives and details of the study were explained in terms of location, schedule, instruments, etc. A meeting was scheduled for all the participants who agreed to participate. The evaluation was performed individually by the researchers at a single meeting of approximately 1 hour and 30 minutes. This collection was performed either at the Institute of Graduation in Psychology, or at the participants' house. First, the participants signed an informed consent form, and then completed the sociocultural questionnaire, MINI, and MMSE. At this moment, psychiatric and neuropsychiatric symptoms were evaluated by a psychologist trained in diagnostic evaluation in older individuals, based on the MINI and MMSE scores and on structured interviews. The interviews were discussed under a neuropsychologist's guidance. Next, participants were submitted to tests evaluating their executive functioning.

\section{Results}

Both groups of elderly had their performance in executive function tasks compared using Student's $t$ test for independent samples. Cognitive functions evaluated in

Table 1.Measures of Central Tendency and Dispersion for the Groups of Young Elderly and the Oldest Old.

\begin{tabular}{llll}
\hline & \multicolumn{3}{c}{ Elderly N $=20 ; \mathrm{M}(\mathrm{SD})$} \\
\cline { 2 - 4 } Task & $\begin{array}{l}\text { Young } \\
(n=10)\end{array}$ & $\begin{array}{c}\text { Oldest old } \\
(n=10)\end{array}$ & $d$ \\
\hline Stroop Color & $57(8.5)$ & $49.6(10.6)$ & 0.77 \\
Stroop Word & $82.1(8.9)$ & $77.7(18.6)$ & 0.32 \\
Stroop Color/Word & $30.5(7.0)$ & $30.8(19.2)$ & 0.02 \\
Digits & $12.7(2.4)$ & $12.6(1.8)$ & 0.04 \\
IGT & $15.4(23.1)^{* *}$ & $-14.6(16.4)^{* *}$ & 1.52 \\
Vocabulary & $11.5(1.3)$ & $12.2(1.0)$ & 0.60 \\
\hline
\end{tabular}

Note. Young elderly and the oldest old significantly differ ** $t(18)=3.34, p<.01$

both groups were: cognitive flexibility (cognitive control in inhibition of usual response) and selective attention (Stroop test), attention, short-term memory and working memory (Digit Span Subtest), semantic knowledge (Vocabulary Subtest), and decision making (IGT). Descriptive statistics were used to confirm parametric inferences (Levene's test showed that for all dependent variables homogeneity of variance could be assumed).

Analyses showed that the groups were only significantly different in terms of decision making ability as measured by the IGT. The group of young elderly had higher mean values $(M=15.4, S D=23.1)$ than the oldest old group $(M=-14.6, S D=6.4), t(18)=$ $3.34, p=.04, d=1.52$, indicating a more advantageous choice skill in the group of young elderly. This result was further qualified by a regression analysis for age (analyzed as a continuous DV) on the total IGT scores which yielded a significant result $(\beta=.-65, t(18)=$ $-3.67, p<.01)$ indicating that age significantly predicted performance in the IGT. Age also explained a significant proportion of variance in IGT scores, $R^{2}=.39, F(1.18)$ 


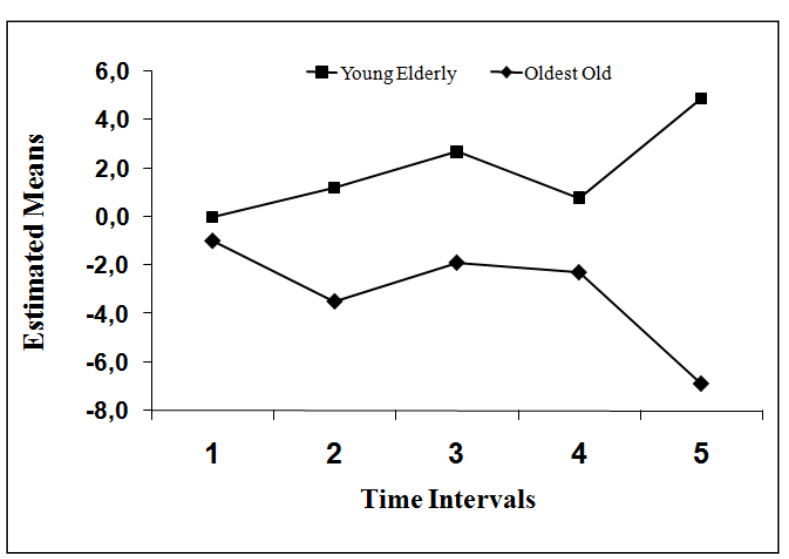

Figure 1. Performance of the groups of young elderly and oldest old during the IGT task.

$=13.5, p<.01$. Group means were not significantly different regarding the other cognitive variables.

When the performance throughout the five decks of 20 cards each in the IGT was analyzed, it was possible to extract data relative to the learning process that participants developed during the task. In the present study, variance analysis (ANOVA for repeated measures) showed a significant difference in the learning process obtained by each group; the group of young elderly reached more favorable scores $F(3.58)=2.94, p<.05, \eta^{2}$ $=.14$ (Figure 1 ). Thus, the young elderly usually tended to progressively choose more cards from advantageous decks, although they had a reduction in the fourth block. On the other hand, the oldest old showed a predominantly disadvantageous choice in their performance since their scores were lower than zero throughout all blocks.

\section{Discussion}

Results pointed to differences in executive functioning between the young elderly and the oldest old as measured by the IGT, and to age as being a predictor of performance in the IGT. This confirms that age, as a categorical but also as a continuous variable, is a factor influencing executive functions as measured by decision making skills, causing reductions in the individual's performance from the sixth decade of life on (Deakin, Aitken, Robbins, \& Sahakian, 2004; Denburg, Tranel, \& Bechara, 2005; Fein, McGillivray, \& Finn, 2007). However, these studies did not consider the cognitive differences that are sometimes present between the young elderly and the oldest old (Baltes, 1998; Baltes \& Smith, 1997; Singer, Lindberger, $\&$ Baltes, 2003); thus, subgroups within the group of elderly individuals are not discriminated.

Considering the complexity of the IGT, which comprehends reasoning as well as emotional processes of executive functioning, prefrontal cortex integrity can be required to reach a satisfactory performance, as this area is known to be involved in higher-order cognitive processes (Lezak, 1995; Spreen \& Strauss, 1998). Due to biological changes resulting from the aging process, it is plausible to infer that the oldest old have even greater difficulties in performing the task, since such difficulties tend to worsen with age.

The considerable difference between the groups as to their rational and emotional learning required during the task showed that the oldest old have an executive impairment compared with the group of young elderly. Their performance indicated failure in constant update of the rational and emotional information regarding each deck, resulting in a behavior of choosing disadvantageous cards throughout all the blocks.

This difference between groups as to their decision making ability, in the absence of divergence in other measurements, may be associated with various explanations. One of them refers to the complexity of the task, which requires the involvement and integration of reasoning and emotional executive processes to be accomplished. Therefore, it could be argued that the worst oldest old performance was due to an age-related decline in emotional processing, since the groups showed a similar performance in more rational tasks (as the Stroop and digits tests). However, this aspect was not directly assessed, since emotional learning was not evaluated on an individual level. Besides, regardless of the emotional processes, the complexity of the task also overloads the cognitive system as a whole by demanding a simultaneous use of basic cognitive resources, such as the case of attention and working memory, which were not different between age groups when tested individually.

Furthermore, although the young elderly and the oldest old form different subgroups, they can be classified as a common age group, namely the third age, demanding increased sensitivity to the task to verify differences. This aspect strengthens the previous argument, since more complex tasks are usually more sensitive.

With regard to the other cognitive processes, many could be the reasons for the absence of differences between groups. Selective attention, measured by Stroop test, did not show significant differences between mean scores of the young elderly and the oldest old, excluding age as an important factor for the inhibitory function of the sample. Other studies evaluating the influence of age on the performance in the Stroop test showed similar results, which do not confirm the universal effect of this variable (Lin et al., 2007; Shilling et al., 2002). The study conducted by Lin et al. (2007) revealed absence of differences between the scores obtained by the young elderly and oldest old in the Stroop test. They performed a study with a sample of 58 healthy elderly individuals divided into two subgroups according to age: one group between 60-70, and the other older than 70 years of age. In addition, regression analyses showed that age explained a small part of the variance in executive functions, while educational level had significant effects on specific components of executive functions, namely initiation, flexibility and updating. 
In the investigation conducted by Shilling et al. (2002), aimed at analyzing inhibitory function using the Stroop test in elderly individuals in two experiments, no significant effects were found on performance. The authors concluded that age may contribute to inhibitory function when considered independently of other variables such as processing speed and intelligence. Both studies found a role of schooling in the performance of elderly individuals in the Stroop test, previously reported by other investigators (Moering, Schinka, Mortimer, \& Graves, 2004; Van der Elst, Van Boxtel, Van Breukelen, \& Jolles, 2006). In general, the data suggested that executive functions, as measured by this instrument, decline with age and that such decline is more marked in those with a low educational level.

In the present sample, the mean educational level (measured by number of years of study) was high for both groups, although not significantly different between them: 15.10 years for the young elderly $(S D=2.2)$ and 13 years for the oldest old $(S D=2.6)$. Therefore, it can be suggested that perhaps the absence of differences between both groups in the Stroop test was partly due to the high educational level of the sample.

The sample data showed no differences between the young elderly and the oldest old in the Digit Span Subtest, which measured selective attention, short-term memory, and working memory. Two other Brazilian studies including samples of the oldest old investigated working memory using the digit span task. In a study performed by Argimon and Stein (2005) the mean score in the Digit Span Subtest was $6.29(S D=2.04)$ in stage I and 4.61 $(S D=2.31)$ in stage II, performed three years later on the same elderly individuals. Although the authors have not compared young elderly and older adults, it is interesting to note that the results were quite lower than those found in the present study $(M=12.6$ points, $S D=1.8$, in the Digit Span Subtest). In another study conducted by Xavier et al. (2006), although the differences between young elderly and older adults were not investigated, the results showed lower scores in the digit span in the oldest old, when compared to our sample. Nevertheless, both studies examined less educated individuals, limiting conclusions about our sample performance.

In a study conducted by Ardila (2007), elderly individuals aged between 65-69 years had a mean of 16 points $(S D=4.2)$; and those aged between $80-84$ years had a mean of 14.5 points $(S D=3.7)$ in the Digit Span Subtest. These results are a little higher than those found in the present study. However, educational level was not specifically described for the elderly population, and that study evaluated participants between 16-89 years. The only information regarding this variable is that $2 / 3$ of the sample had 12 years of study or more.

Based on the results, the high educational level of the sample may have played a major role in the data obtained, since it is commonly associated with greater cognitive preservation. This is in agreement with Ardila et al. (2000), who claim that cognitive changes throughout life are affected by education, and that this relationship is dependent on the cognitive domain. In our sample, the high educational level seems to have resulted in a lower difference between both groups, which was not extended to the decision making ability.

Considering the exposed so far, although the influence of educational level on the performance of individuals in the IGT has been observed, resulting in a worse performance in the presence of a higher educational level (Evans, Kemish \& Turnbull, 2004), its effect still needs further evidence. In addition, normative data from a sample of 932 healthy participants minimized its importance by showing that schooling years accounted for $0.3 \%$ out of a $3.6 \%$ variance between IGT scores (Bechara, 2007).

Some methodological limitations require careful consideration of the findings in this study. One refers to the reduced sample size, which restricts the generalization power of the data. In addition, both groups had more than 12 years of study, which does not provide answers about maintenance of results in populations with lower educational levels. That is, our results only provide evidence for individuals' performance in the IGT when higher educated samples are taken into account. In this sense, these findings are still preliminary and further research should be conducted using larger samples and oldest old individuals with lower educational level for a better investigation of the aspects analyzed in this study. Other suggestions for future studies are to compare different groups regarding their educational level (i.e., low vs. intermediate vs. high educational level) and to investigate factors that can predict cognitive performance.

\section{References}

Amorim, P. (2000). Mini International Neuropsychiatric Interview (M.I.N.I): Validação de entrevista breve para diagnóstico de transtornos mentais. Revista Brasileira de Psiquiatria, 3, 106-115.

Ardila, A. (2007). Normal aging increases cognitive heterogeneity: Analysis of dispersion in WAIS-III scores across age. Archives of Clinical Neuropsychology, 22, 1003-1011.

Ardila, A., Ostrosky-Solis, F., Rosselli, M., \& Gómes, C. (2000). Age-related cognitive decline during normal aging: The complex effect of education. Archives of Clinical Neuropsychology, 15(6), 495-513.

Argimon, I.I.L., \& Stein, L.M. (2005). Habilidades cognitivas em indivíduos muito idosos. Cadernos de Saúde Pública, 21(1), 64-72.

Baldelli, M.V., Salvioli, G., Neri, M., \& Pradelli, J.M. (1996). A survey of a centenarian population in Italy, focusing on self-sufficiency and cognition. Archive of Gerontology and Geriatric, 5, 345-354.

Baltes, M.M. (1998). The psychology of the oldest-old: the fourth age. Geriatric Psychiatry, 11(4), 411-415.

Baltes, P.B., \& Smith, J. (1997). A systemic-holistic view of psychological functioning in very old age: Introduction to a collection of articles from the Berlin aging study. Psychology and Aging, 12(3), 395-409.

Bechara, A. (2007). Iowa Gambling Task - Professional Manual. USA: Psychological Assessment Resources.

Bechara, A., Damasio, A.R., Damasio, H., \& Anderson, S. (1994). Insensitivity to future consequences following damage to human prefrontal cortex. Cognition, 50, 7-15.

Carey, C.L., Kramer, J.H., Josephson, A., Mungas, D., Reed, B.R., Schuff, R., Weiner, M.W., \& Chui, H.C. (2008). Subcortical lacunes are associated with executive dysfunction in cognitively 
normal elderly. Stroke, 39 (2), 397-402.

Chaves, M.L., \& Izquierdo, Y. (1992). Differential diagnosis between dementia and depression: A study of efficiency increment. Acta Neurologica Scandinavia, 85, 378-382.

Cowell, P.E., Turetsky, B.I., Gur, R.C., Grossman, R.I., Shtasel, D.L., \& Gur, R.E. (1994). Sex differences in aging of the human frontal and temporal lobes. The Journal of Neuroscience, 14, 4748-4755.

Cunha, J.A. (2000). Psicodiagnóstico-V. Porto Alegre: Artmed.

Deakin, J.B., Aitken M.R.F., Robbins, T.W., \& Sahakian, B.J. (2004) Risk taking during decision-making in normal volunteers changes with age. Journal of the International Neuroscience Society, $10,590-598$

Denburg, N., Tranel, D., \& Bechara, A. (2005). The ability to decide advantageously declines prematurely in some normal older persons. Neuropsychologia, 43(7). 1099-1106.

Evans, C.E., Kemish, H., \& Turnbull, O.H. (2004). Paradoxal effects of education on the Iowa Gambling Task. Brain and Cognition, 54(3), 240-244.

Fein, G., McGillivray, S., \& Finn, P. (2007). Older adults make less advantageous decisions than younger adults: cognitive and psychological correlates. Journal of the International Neuropsychology Society, 13, 480-489.

Finuncane, M.L., Alhakami, A., Slovic, P., Hibbard, J.H., Peters, E., Mertz, C.K., \& MacGregor, D.G. (2002). Aging and decision making competence: An analysis of comprehension and consistency skills in older versus younger adults considering healthplan options. Journal of Behavioral Decision Making, 15(2), 141-164.

Glisky, E.L., \& Kong, L. (2008). Do young and older adults rely on different processes in source memory task? A neuropsychological study. Journal of Experimental Psychology: Learning, Memory, and Cognition, 34(4), 809-822.

Golden, C.J. (1978). Stroop Color and Word Test: A Manual for Clinical and Experimental Uses. Chicago, IL: Stoelting Co.

Haug, H., \& Eggers, R. (1991). Morphometry of the human cortex cerebri and corpus striatum during aging. Neurobiology of $\mathrm{Ag}$ ing, 12, 336-338.

Hoshide, S., Ishikawa, J., Eguchi, K., Oowada, T., Shimada, K., \& Kario, K. (2008)._Cognitive dysfunction and physical disability are associated with mortality in extremely elderly patients. $\mathrm{Hy}$ pertension Research, 31(7), 1331-8.

Kahneman, D. (2003). A perspective on judgement and choice. American Psychologist, 58, 697-720.

Lezak, M.D. (1995). Neuropsychological assessment. New York: Oxford University Press.

Lin, H., Chan, R.C.K., Zheng, L., Yang, T., \& Wanga,Y. (2007). Executive functioning in healthy elderly Chinese people. Archives of Clinical Neuropsychology, 22, 501-511.

Lindenberger, U., \& Baltes, P.B. (1997). Intellectual functioning in old and very old age: Cross-sectional results from the Berlin aging study. Psychology and Aging, 12(3), 410-432.

Moering, R.G., Schinka, J.A., Mortimer, J.A., \& Graves, A.B. (2004). Normative data for elderly African Americans for the Stroop Color and Word Test. Archives of Clinical Neuropsychology, 19, 61-71.

Mungas, D., Reed, B.R., \& Kramer, J.H. (2003). Psychometrically matched measures of global cognition, memory, and executive function for assessment of cognitive decline in older person. Neuropsychology, 17(3), 380-392.

Nascimento, E. (2000). WAIS-III. In: J.A. Cunha (Ed.), PsicodiagnósticoV (pp. 615-627). Porto Alegre: Artmed.

Parkin, A.J. (1993). Getting old. In: A.J. Parkin (Ed.), Memory phenomena, experiment and theory (pp. 172-195). Cambridge, USA: Blackwell.

Raz, N., Gunning, F.M., Head, D., Dupuis, J.H., McQuain, J., Briggs,
S.D., Loken, W. J., Thornton, A.E., \& Acker, J.D. (1997). Selective aging of the human cerebral cortex observed in Vivo: Differential vulnerability of the prefrontal gray matter. Cerebral Cortex, 7, 268-282.

Raz, N., Lindenberger, U., Rodrigue, K., Kennedy, K.M., Head, D., Williamson, A., Dahle, C., Gerstorf, D., \& Acker, J.D. (2005). Regional brain changes in aging healthy adults: General trends, individual differences and modifiers. Cerebral Cortex, 15, 1676-1689.

Schneider, D. \& Parente, M.A.M.P. (2006). O desempenho de jovens e idosos na Iowa Gambling Task (IGT): Um estudo sobre a tomada de decisão. Psicologia: Reflexão e Crítica, 19(3), 442-450.

Sheehan, D., Lecrubier, Y., Sheehan, K.H., Amorim, P., Janavs, J., Weiller, E. et al. (1998). The Mini International Neuropsychiatric Interview (M.I.N.I.): The development and validation of a structured diagnostic psychiatric interview for DSM-IV and CID-10. Journal of Clinical Psychiatry, 59(20), 22-33.

Shilling, V.M, Chetwynd, A., \& Rabbitt, P.M.A. (2002). Individual inconsistency across measures of inhibition: An investigation of the construct validity of inhibition in older adults. Neuropsychologia, 40, 605-619.

Singer, T., Lindenberg, U., \& Baltes, P.B. (2003). Plasticity of memory for the new learning in very old age: A story of major loss? Psychology and Aging, 18(2), 306-317.

Smith, J., \& Baltes, P.B. (1997). Profiles of psychological functioning in the old and oldest old. Psychology and Aging, 12(3), 495-472.

Spencer, W.D., \& Raz, N. (1994). Memory for facts, source, and context: Can frontal lobe dysfunction explain age-related differences? Psychology and Aging, 9(1), 149-159.

Spreen, O., \& Strauss, E. (1998). A compendium of neuropsychological tests: Administration, norms and commentary. New York: Oxford University.

Stroop, J.R. (1935). Studies of interference in serial verbal reactions. Journal of Experimental Psychology, 18(6) 643-662.

Van der Elst, W., Van Boxtel, M.P.J., Van Breukelen, G.J.P., \& Jolles, J. (2006). The Stroop Color-Word Test: Influence of age, sex, and education; and normative data for a large sample across the adult age range. Assessment, 13, 62-79.

Verhaeghen, P., \& De Meersman, L. (1998). Aging and the Stroop effect: A meta-analysis. Psychology and Aging, 13(1), 120-126.

Wecker, N.S., Kramer, J.H., Hallam, B.J., \& Delis, D.C. (2005). Mental flexibility: Age effects on switching. Neuropsychology, 19(3), 345-352.

Wechsler, D. (1997). WAIS-III: Escala de Inteligência Wechsler para adultos - manual David Wechsler. Adaptação e padronização de uma amostra brasileira. Elizabeth do Nascimento ( $1^{\text {a }}$ ed.). São Paulo: Casa do Psicólogo.

West, R.L. (1996). An application of prefrontal cortex function theory to cognitive aging. Psychological Bulletin, 120, 272-292.

West, R. (2000). In defense of the frontal lobe hypothesis of cognitive aging. Journal of the International Neuropsychological Society, 6, 727-729.

Xavier, F., Argimon, I.I.L., Zuppo, L., Lucchesi, L.M.S, Heluanyc, C.C.V., \& Trentini, C.M. (2006). O desempenho em testes neuropsicológicos de octogenários não-dementes e com baixa escolaridade em duas comunidades do sul do Brasil. PsicoPUCRS, 37(3), 221-231.

Xavier, F., Ferraz, M.P.T., Bisol, L.W., Fernandes, D.D., Schwanke, C., \& Moriguchi, E.H. (2000). Octogenarians of Veranópolis: The psychological, social and health conditions of a representative group over the age 80 living in the community. Revista da AMRIGS, 44(1/2), 25-29.

Yang, L., Krampe, R.T., \& Baltes, P.B. (2006). Basic forms of cognitive plasticity extended into the oldest-old: Retest learning, age, and cognitive functioning. Psychology and Aging, 21(2), 372-378. 